\title{
Prescrição de medicamentos e solicitação de exames por enfermeiros no PSF: aspectos, éticos e legais ${ }^{1}$
}

\section{Prescripción de los medicamentos y solicitación de examen por enfermeros en el PSF: aspectos, éticos y legáis}

\section{Medicine prescription and test request by nurse in FHP: ethics and legal aspects.}

\author{
Alan Dionizio Carneiro', Gilvânia Smith da Nóbrega Morais", Solange Fátima Geraldo da Costa"', \\ Patrícia Serpa de Souza Batistalv, Kalina Coeli da Costav
}

\begin{abstract}
RESUMO
O Programa Saúde da Família - PSF - surge como proposta para reorientar e reorganizar o sistema público, assegurando a construção de um modelo assistencial que priorize a cidadania de todos. O enfermeiro, como membro da equipe de saúde da família, exerce um papel extremamente importante, desenvolvendo ações comuns a toda equipe e outras atribuições específicas, como, por exemplo, realizar consulta de enfermagem, solicitar exames complementares e prescrever medicamentos em condições singulares. No que concerne à prescrição de medicamentos e solicitação de exames por enfermeiros no PSF, têm surgido muitos questionamentos, envolvendo o respaldo legal diante de tais atribuições. Neste enfoque, o presente estudo de natureza documental tem por objetivo destacar parâmetros éticos e legais que respaldem a prática de enfermeiros no PSF referente à prescrição de medicamentos e solicitação de exames. Vale ressaltar que, para a concretude deste trabalho, foram enfatizados a Lei do Exercício Profissional 7.498/86, o Decreto 94.406/87, o Código de Ética dos Profissionais de Enfermagem - Resolução COFEN 311/07 e a Resolução COFEN 271/02. A partir deste estudo, pôde-se observar que a consolidação destas práticas realizadas pelo enfermeiro, no PSF, fazem-se necessárias na construção da legitimidade e identidade profissional do enfermeiro.
\end{abstract}

Palavras chave: Enfermagem Forense. Ética. Programa Saúde da Família.

\section{ABSTRACT}

The Family Health Program (FHP), is a proposal that aims to guide and organize the public system, assuring the construction of an assistance model that gives priority to all citizens. The nurse, as a member in this program plays an important role, developing actions that are common to the role team as well as, some other specifics actions such as nurse consultation, request of complementary tests and medicine prescription. Concerning to medicine prescription and request of tests there have been many questions involving the legal validity of those procedures. In this sense, this is a documental study that aims to point out the ethics and legal parameters that supports the practice of nurses in the FHP, concerning to medicine prescription and request of tests. It can be pointed out that his study was based upon the law of professional practice 7.498/86; the decree 94.406/87; the Ethic Code of Nurse Professional; resolution of COFEN 311/07 and the resolution of COFEN 271/02. According to the findings of this study, it was observed that the consolidation of the practices performed by nurses in the FHP, are of fundamental importance in the process of legitimation and professional identity of nurse.

Key words: Nurse Legislation. Ethics. Family Health Program

\section{RESUMEN}

El programa de la salud de la familia-PSF surge como propuesta para reorientar y reestructurar

\footnotetext{
${ }^{1}$ Trabalho Premiado na modalidade Oral apresentado no IX CBCENF - 2006.

Graduado em Enfermagem. Mestrando do Programa de Pós- Graduação em Enfermagem da UFPB. E-mail: gaufpb@msn.com.

"Graduada em Enfermagem. Mestre em Enfermagem pela UFPB. Docente do Curso de Graduação em Enfermagem UFCG. E-mail: ga anjim@hotmail.com.

III Enfermeira. Doutora em Enfermagem pela EERP - USP. Docente dos Cursos de Graduação e Pós-Graduação em Enfermagem do CCS/UFPB. E-mail: solangefgc@gmail.com. IV Enfermeira. Mestre em Enfermagem pela UFPB. Docente do Curso de Graduação em Enfermagem do CCS/UFPB. Email: patriciaserpa@oi.com.br.

$\checkmark$ Graduada em Enfermagem. Especialista em Saúde da Família. Docente da Escola Técnica de Saúde - UFCG. Email: kalinacoeli@gmail.com.
} 
Carneiro AD, Morais GSN, Costa SFG, Batista PSS, Costa KC. Prescrição de medicamentos e solicitação de exames por enfermeiros no PSF: aspectos éticos e legais. Rev. Eletr. Enf. [Internet]. 2008; 10(3):756-65. Available from: http://www.fen.ufg. br/revista/v10/n3/v10n3a21.htm

el sistema público, garantizando la construcción e un modelo de la asistencia que privilegie la ciudadanía de los todos. El enfermero, por lo tanto miembro de la equipo de la salud de la familia tiene una posición muy importante, desarrollando acciones comunes a la todo equipo y otros atribución especificas con por ejemplo, la realización de la consulta de enfermería, solicitación de examen complementares y la prescripción de los medicamentos en condiciones singulares. En lo que hace respecto a la prescripción y solicitación de examen por enfermeros en el PSF, han surgido muchas contestaciones, envolviendo el respaldo legal delante de estas atribuciones. En este enfoque, el presente estudio de la naturaleza documental, tiene como objetivo destacar parámetros éticos y

\section{CONSI DERAÇÕES I NI CI AIS}

No Brasil, após a promulgação da Constituição Federal em 1988, a saúde passa a ser compreendida como direito de todos e dever do poder público, para tanto prevê a construção do Sistema Único de Saúde (SUS), desenvolvido sobre os pilares da universalidade, eqüidade, igualdade e descentralização, priorizando ações de promoção, proteção, prevenção e recuperação da saúde.

No entanto, as políticas públicas não vêm favorecendo de modo efetivo, o estabelecimento de um modelo de atenção integral, mas vêm contribuindo para a disseminação da idéia de que a saúde se concretiza, exclusivamente ou prioritariamente, mediante o acesso a serviços, em especial ao tratamento médico, resultando, conseqüentemente, numa assistência baseada em ações curativas e, portanto, quando a doença já está instalada(1). Este panorama caracteriza o que se denomina de modelo hospitalocêntrico, pelo qual ocorre a valorização da doença e sua institucionalização, bem como a valorização do desenvolvimento tecnocientífico que subsidia as práticas curativas.

Contudo, é oportuno destacar que este modelo não atende mais às expectativas do mundo moderno, no que concerne às necessidades de saúde, uma vez que tem feito parte do cenário brasileiro, aspectos que o caracterizam como um país de terceiro mundo legáis que respalden la practica de enfermeros en el PSF que se réferi a la prescripción de los medicamentos y solicitación de examen. Vale decir que para la realización del trabajo, fueron enfatizados la ley del ejercicio profesional 7.498/86, el Decreto 94.406/87, el código de la ética de los profesionales de enfermeríaResolución COFEN 311/07 y la Resolución COFEN 271/02. a partir de este estudio, puédase observar que la consolidación de estas practicas realizadas por el enfermero, el PSF, se hace necesaria en la construcción de la legitimidad y identidad profesional del enfermero.

Palabras clave: Legislación en Enfermería. Ética. Programa de la Salud de la Familia

bem como situações eminentemente de países desenvolvidos. Nesta perspectiva, ao mesmo tempo em que persistem as doenças infectocontagiosas, observa-se um aumento das doenças crônico-degenerativas, além de crescerem as causas externas (acidentes, homicídios entre outros).

Diante dessas adversidades existentes no cotidiano da saúde brasileira, houve a necessidade de adotar novos tipos de ações na saúde que pudessem gerar mudança no modelo de atenção vigente. Neste contexto, emerge o Programa Saúde da Família - PSF. Este foi criado, em 1994, pelo Ministério da Saúde, tendo, portanto, como proposta reorientar e reorganizar o sistema público tradicional, impulsionando o cuidar em saúde para as realidades concretas da população e, com isso, melhorar a qualidade de vida das pessoas, priorizando ações de saúde, a partir de uma visão holística e contínua do cuidado.

O PSF constitui uma estratégia: “( ...) de reforma incremental do sistema de saúde no Brasil, tendo em vista que o programa aponta para mudanças importantes na forma de remuneração das ações de saúde (superação da exclusividade do pagamento por procedimentos), nas formas de organização dos serviços e nas práticas assistenciais no plano local e, portanto, no processo de descentralização"(2). 
Carneiro AD, Morais GSN, Costa SFG, Batista PSS, Costa KC. Prescrição de medicamentos e solicitação de exames por enfermeiros no PSF: aspectos éticos e legais. Rev. Eletr. Enf. [Internet]. 2008; 10(3):756-65. Available from: http://www.fen.ufg.br/revista/v10/n3/v10n3a21.htm

No Programa de Saúde da Família, temos a família e a comunidade como porta de entrada deste sistema, cuja capacidade se propõe a cuidar da população e não somente da doença, assegurando a construção de um modelo assistencial que priorize a cidadania de todos, intersetorial, universal, eqüitativo a todos os níveis necessários à atenção integral à saúde.

É oportuno destacar que o enfermeiro, como membro da equipe de saúde da família, exerce um papel extremamente importante no PSF, incluindo ações comuns a toda equipe e outras que Ihes são prioritárias como, por exemplo, realizar consulta de enfermagem, solicitar exames complementares, prescrever medicamentos, executar ações de assistência integral em todas as fases do ciclo de vida do ser humano, entre outras.

Entretanto, no que se refere à prescrição de medicamentos e solicitação de exames por enfermeiros no PSF, têm surgido muitos questionamentos que envolvem o respaldo legal de tais atribuições, daí o nosso interesse em realizar um estudo de natureza documental, tendo como objetivo destacar parâmetros éticos e legais que respaldam a prática de enfermeiros no PSF, no que concerne à prescrição de medicamentos e solicitação de exames.

\section{CONSI DERAÇÕES METODOLÓGI CAS}

Trata-se de uma pesquisa de natureza documental, organizada com base nas seguintes etapas operacionais:

1a etapa: seleção de documentos normativos relacionados à prescrição de medicamentos e solicitação de exames na prática de enfermagem. Neste primeiro momento, após um levantamento dos documentos normativos, no que concerne à prática de enfermagem, os autores selecionaram aqueles inerentes à prescrição de medicamentos e solicitação de exames por enfermeiros, incluindo a Lei do Exercício Profissional 7.498/86, o Decreto 94.406/87, o Código de Ética dos Profissionais de Enfermagem - Resolução COFEN 311/07, a Resolução COFEN 195/97 e a Resolução COFEN 271/02;

2a etapa: identificação, a partir dos documentos selecionados, dos artigos mais relevantes inerentes à prescrição de medicamentos e solicitação de exames por enfermeiros. Nesta etapa, foram extraídos os artigos relacionados ao tema em destaque; da Lei do Exercício Profissional, foi selecionado o artigo 11으, incisos I (alíneas c, i, j) e II (alínea (b,c); do Decreto, extraiu-se o artigo 8o, incisos I (alíneas a,f,h) e II (alíneas b, c, g, i); no que se refere ao Código de Ética dos Profissionais de Enfermagem, foram destacados 0 texto dos Princípios Fundamentais, os artigos 12, 30, 31 e 32, da Seção I, das Relações com a Pessoa, Família e Coletividade (Responsabilidades e Deveres; Proibições); da Resolução 195/97, foi enfatizado o artigo primeiro; e da Resolução 271/02, foram destacados os artigos $1 ㅇ, 2 \circ, 3 \circ, 4 ㅇ, 5 ㅇ$ e 60 ;

3a etapa: construção do texto, visando ao alcance do objetivo proposto pela investigação. Nesta etapa, foi elaborada a redação final do texto, contemplando os aspectos éticos e legais, no que se refere à prescrição de medicamentos e solicitação de exames que respaldam a prática de enfermagem no PSF.

Vale ressaltar que os pesquisadores levaram em consideração as observâncias éticas contempladas no Código de Ética dos Profissionais de Enfermagem - Resolução 311/07 do Conselho Federal de Enfermagem, no que se refere à elaboração de trabalhos científicos, como mostra os artigos a seguir: CAPÍTULO III - DO ENSINO, DA PESQUISA E DA PRODUÇÃO TÉCNICO-CIENTÍFICA

Responsabilidades e Deveres “Art. 91. Respeitar os princípios da honestidade e fidedignidade, bem como os direitos autorais no processo de pesquisa, especialmente na divulgação dos seus resultados"; - Proibições "Art. 100. Utilizar sem referência ao autor ou sem a sua autorização expressa, dados, informações, ou opiniões ainda não publicados"; CAPÍTULO IV - DA PUBLICIDADE - Direitos “Art. 103. Utilizar-se de veículo de: comunicação para conceder entrevistas ou divulgar eventos e assuntos de sua competência, com finalidade educativa e de interesse social"; - Responsabilidades e Deveres “Art. 105. Resguardar os princípios da honestidade, veracidade e fidedignidade no conteúdo e na forma publicitária. Art. 106. Zelar 
Carneiro AD, Morais GSN, Costa SFG, Batista PSS, Costa KC. Prescrição de medicamentos e solicitação de exames por enfermeiros no PSF: aspectos éticos e legais. Rev. Eletr. Enf. [Internet]. 2008; 10(3):756-65. Available from: http://www.fen.ufg.br/revista/v10/n3/v10n3a21.htm

pelos preceitos éticos e legais da profissão nas diferentes formas de divulgação."(3).

\section{Considerações gerais acerca do enfermeiro no Programa Saúde da Família}

O modelo assistencial proposto pelo PSF enfatiza medidas direcionadas à manutenção da saúde focalizada no indivíduo, estendendo-se à família e à comunidade. Portanto, este programa busca atender o indivíduo em seu contexto familiar, priorizando ações de promoção e proteção à saúde, a partir de uma equipe multiprofissional composta, no mínimo, por um Médico generalista, um Enfermeiro, um Auxiliar de Enfermagem e Agentes Comunitários de Saúde (ACS), podendo incorporar outros profissionais de saúde como Odontólogo, Atendente de Consultório Dentário (ACD), Nutricionista, Fisioterapeuta entre outros, de acordo com as demandas e características da organização dos serviços de saúde locais ${ }^{(4)}$.

É oportuno ressaltar que a participação do enfermeiro na equipe do PSF merece destaque, ao mesmo tempo em que constitui um desafio, uma vez que, “(...) deve levar em consideração o envolvimento do seu agir com os aspectos sociais, políticos, econômicos e culturais relevantes para o processo de transição e consolidação do novo modelo de assistência à saúde"(5).

Portanto, o enfermeiro, a partir do contexto sócio-político e econômico que interfere diretamente no processo saúdedoença, deve levar em consideração as reais necessidades presentes na comunidade, subsidiando meios que possibilitem uma resolução satisfatória diante dos problemas evidenciados.

Vale salientar que o enfermeiro, "trabalhando com as reais necessidades locais, por meio de uma prática apropriada, humanizada ao considerar o indivíduo em sua integralidade e tecnicamente competente, sincronizando o saber popular com o saber técnico científico, em um verdadeiro encontro de gente cuidando de gente", gera novas práticas que englobam tanto $a$ atenção individual como a coletiva ${ }^{(6)}$.

O enfermeiro, como membro do PSF exerce atribuições que possibilitam sua consolidação, incluindo ações que vão desde o planejamento até a assistência propriamente dita, o que torna sua prática diferente daquela que ocorre em instituições estruturadas no modelo tradicional. "O papel desempenhado pelo enfermeiro no PSF contrasta com a indefinição existente em outros espaços de trabalho, marcados pelas diferentes atividades, nem sempre compatíveis com a sua formação profissional. A indefinição de papéis, o desprestígio social e a falta de autonomia tão comentados na literatura, assim como acomodação e a apatia desse profissional diante de tal situação são marcas da trajetória profissional desses trabalhadores"(7).

Sob esse prisma, observa-se que o Programa Saúde da Família tem contribuído para definir a prática do enfermeiro como categoria profissional voltada para promover a saúde e o bem-estar do ser humano em todo seu ciclo vital. Para uma melhor compreensão acerca das ações desempenhas pelo enfermeiro no PSF, a seguir serão apresentadas as que lhes são prioritárias: "realizar cuidados diretos de enfermagem nas urgências e emergências clínicas, fazendo a indicação para a continuidade da assistência prestada; realizar consulta de enfermagem, solicitar exames complementares, prescrever/transcrever medicações, conforme protocolos estabelecidos nos Programas do Ministério da Saúde e as disposições legais da profissão; planejar, gerenciar, coordenar, executar e avaliar a USF; executar as ações de assistência integral em todas as fases do ciclo de vida: criança, adolescente, mulher, adulto e idoso; no nível de suas competências, executar assistência básica e ações de vigilância epidemiológica e sanitária; realizar ações de saúde em diferentes ambientes, na USF e, quando necessário, no domicílio; realizar as atividades correspondentes às áreas prioritárias de intervenção na Atenção Básica, definidas na Norma Operacional da Assistência à Saúde NOAS 200.1; aliar a atuação clínica à prática da saúde coletiva; organizar e coordenar a criação de grupos de patologias específicas, como de hipertensos, de diabéticos, de saúde mental, etc; supervisionar e coordenar ações para capacitação dos Agentes Comunitários de Saúde 
Carneiro AD, Morais GSN, Costa SFG, Batista PSS, Costa KC. Prescrição de medicamentos e solicitação de exames por enfermeiros no PSF: aspectos éticos e legais. Rev. Eletr. Enf. [Internet]. 2008; 10(3):756-65. Available from: http://www.fen.ufg.br/revista/v10/n3/v10n3a21.htm

e de auxiliares de enfermagem, com vistas ao desempenho de suas funções" ${ }^{\prime(8)}$.

Observa-se, portanto, que o enfermeiro exerce um papel relevante na atenção à saúde do indivíduo, família e comunidade e que, a partir destas ações que lhes são prioritárias, ele assume atribuições que torna reconhecida a prática de enfermagem. Entretanto, apesar do reconhecimento e valorização das atribuições do enfermeiro no PSF, no que tange à prescrição de medicamentos e solicitação de exames, ele tem enfrentado alguns obstáculos.

\section{Prescrição e solicitação de exames por enfermeiros no PSF}

O Programa de Saúde da Família tem possibilitado à enfermagem, avanços no saber e no fazer, mediante a construção de um espaço assistencial ímpar para o enfermeiro, percebendo-o como um profissional fundamental e essencial na execução e seguimento das ações de saúde, evolvendo desde as intervenções diretas através da consulta e prescrição de medicamentos até as intervenções indiretas como no fenômeno da educação em saúde para a população. 0 reconhecimento do papel do enfermeiro no programa permite, não obstante às normas que regem a profissão, a construção da identidade profissional do enfermeiro.

Entretanto, a construção de uma identidade profissional do enfermeiro procura estabelecer e reivindicar o que é próprio, característico e de competência deste profissional da saúde, inserido numa equipe multidisciplinar, gerando, por vezes, discussões sobre a capacidade técnica e jurídica do enfermeiro frente às suas atribuições no PSF, na tentativa de que a interface com outras áreas da saúde não seja considerada uma invasão(7).

$$
\text { Nesta perspectiva, encontram-se }
$$
discussões sobre a prescrição de medicamentos e a solicitação de exames por enfermeiros no PSF, nas quais profissionais médicos afirmam serem atribuições específicas de sua profissão. Para refutarmos tais alegações, faz-se necessário perquirirmos quais os parâmetros legais que subsidiaram as referidas práticas no PSF.
Urge, primeiramente, ressaltarmos a Lei Federal 7.498/86, a qual dispõe sobre o exercício da profissão de enfermagem nas três categorias: enfermeiro, técnico de enfermagem e auxiliar de enfermagem, além de outros profissionais por ela abarcados. A referida lei é considerada inovadora por delinear, em seu artigo 11, as ações privativas do enfermeiro, no inciso I, dentre elas, a consulta de enfermagem, bem como as ações do enfermeiro como membro da equipe, destacando-se a alínea " $c$ " a qual permite ao enfermeiro prescrever medicamentos estabelecidos em programas de saúde pública e em rotina aprovada por instituição de saúde ${ }^{(9)}$.

Em consonância com a Lei $7.498 / 86$, o decreto $94.406 / 87$ que a regulamenta estabelece, no cerne das atribuições como membro da equipe (art. 8,II, c), que os medicamentos que podem ser prescritos por enfermeiros, nos programas de saúde pública devem estar previamente estabelecidos, oportunizando assim um melhor preparo e segurança do enfermeiro no ato de prescrevêlos. Respeitados esses ditames jurídicos, o enfermeiro não incorre jamais em desvio de competência $^{(10)}$.

No que concerne aos parâmetros, ou seja, o modus operandi, que regem tais prescrições, o Conselho Federal de Enfermagem - COFEN -, no gozo de suas prerrogativas, promulgou a Resolução no 271/2002, discorrendo sobre a prescrição de medicamentos, a requisição de exames, além da consulta de enfermagem, a fim de melhor contribuir para o bom exercício da profissão de enfermagem, a consecução dos serviços de saúde e solucionar os problemas da população.

Note-se, quanto à prescrição, que o referido documento normativo reafirma, nos artigos 1 ㅇ e $2^{\circ} \circ$, os dispositivos contidos na Lei 7.498/86 e no Decreto $94.406 / 87$, realçando que 0 ato de prescrever do enfermeiro, como integrante da equipe de saúde, tem como limite os programas de saúde pública e as rotinas aprovadas por instituições de saúde.

Entretanto, a Resolução COFEN 271/2002 tem enfrentado embates jurídicos, iniciados após um ano de sua vigência e que, embora a enfermagem tenha ganhado vários destes, a 
Carneiro AD, Morais GSN, Costa SFG, Batista PSS, Costa KC. Prescrição de medicamentos e solicitação de exames por enfermeiros no PSF: aspectos éticos e legais. Rev. Eletr. Enf. [Internet]. 2008; 10(3):756-65. Available from: http://www.fen.ufg.br/revista/v10/n3/v10n3a21.htm

decisão mais recente do Tribunal Federal da $1 \underline{\underline{a}}$ Região (TRF-1) sobre 0 processo $\mathrm{n}$ ㅇ 2002.34.00.036024-8 proposto pelo Sindicato Médico do Rio Grande do Sul (SIMERS) contra o COFEN, não nos foi favorável, suspendendo os arts. do 3 o ao 6일 $^{(11)}$. Vale ressaltar que, apesar dos efeitos da decisão incidirem diretamente sob a Resolução em questão, dizendo respeito apenas às partes, a prática da prescrição de medicamentos continua resguardada pela Lei e - Decreto que regulamentam a profissão de enfermagem.

Neste viés, urge evidenciarmos melhor as discussões que envolvem a Resolução 271/2002, numa abordagem apologética, a fim de compreendermos a relevância deste documento para os enfermeiros, em especial, aqueles que se enquadram no Programa de Saúde da Família. O artigo 3 o da Resolução em questão possui a seguinte redação: “O Enfermeiro, quando no exercício da atividade capitulada no artigo 1ㅇ, tem autonomia na escolha dos medicamentos e respectiva posologia, respondendo integralmente pelos atos praticados"(12).

Um dos aspectos conflitantes nesse artigo diz respeito à autonomia do enfermeiro sobre o ato de prescrever medicamentos o que, nesse caso, segundo o Conselho Federal de Medicina CFM -, não the seria possível legalmente ${ }^{(13)}$. Convém, então, destacar que o termo autonomia, no texto, não significa independência do profissional, num agir livre, por si próprio. Isto seria um contra-senso, já que a base do documento são os programas de saúde pública cujos soerguimentos se dão no âmbito da multi e interdisciplinaridade ${ }^{(10)}$.

A autonomia consiste na capacidade do sujeito (enfermeiro) em autodeterminar-se que, "em última instância, diz respeito à cidadania", ou seja, exercício dos direitos e deveres que the competem. Aplicando-se ao dilema em questão, nada mais seria do que reivindicar que 0 enfermeiro ocupe o lugar que lhe foi garantido em conformidade com a lei, assim como a Resolução 271/2002, não prevê que o enfermeiro prescreva arbitrariamente, enquanto ato privativo. Ao contrário, deve fazê-lo, em concomitância com as atribuições que lhe foram asseguradas pela equipe multiprofissional planejadora do programa, o que denota que a autonomia do enfermeiro é relativa às regras dos programas de saúde pública(14).

Ademais, o verbo utilizado na legislação em enfermagem é 'prescrever', e não 'transcrever', que indicaria submissão, dependência excessiva em relação ao profissional médico, confundindo o enfermeiro como mero despachante de receituários e medicações. Entretanto, o termo 'prescrever' requer por si só certa autonomia, conquistada mediante os cursos de aperfeiçoamento/ capacitação específicos para profissionais em programas de saúde pública, muitas vezes oferecidos pelo próprio governo, sendo acrescidos da criticidade científica, da visão de mundo, abarcada durante a aquisição do diploma de enfermeiro e que, portanto, possui igualdade de condições para tomar decisões na equipe de saúde da família(7).

A autonomia relativa e a criticidade favorecem não só a capacidade do enfermeiro em prescrever como também em escolher o medicamento e sua respectiva posologia. Desta maneira, pode o enfermeiro sobrepor seu olhar, isento de coerção por outro profissional, sob a individualidade e reais necessidades do paciente, o que implica identificar o problema de saúde do paciente (diagnóstico), desde que essas medidas compactuem com os problemas de saúde combatidos pelo Programa de Saúde da Família, que sejam de competência do enfermeiro e tenham sido evidenciadas através da consulta de enfermagem.

Sendo assim, tornar-se-ia incongruente um programa de saúde pública que viesse a ser planejado sem o parecer de um médico ou enfermeiro profissionais partícipes desse programa, que discorresse sobre as atribuições de cada integrante da equipe, expondo suas contribuições; explorando, por exemplo, situações, condições e casos em que o enfermeiro poderia atuar na prescrição de medicamentos e na solicitação de exames. Logo, uma equipe composta na multi e interdisciplinaridade deve analisar as atribuições/ competências científicas, técnicas e legais de todos os membros que executarão os programas, a fim de, com isso, dar eficácia e eficiência a estes. 
Carneiro AD, Morais GSN, Costa SFG, Batista PSS, Costa KC. Prescrição de medicamentos e solicitação de exames por enfermeiros no PSF: aspectos éticos e legais. Rev. Eletr. Enf. [Internet]. 2008; 10(3):756-65. Available from: http://www.fen.ufg. br/revista/v10/n3/v10n3a21.htm

A Resolução 271/2002, em seu artigo 3으, termina sua redação com preocupação idêntica àquela com que se inicia 0 4으 artigo, reconhecendo a responsabilidade ética e civil do enfermeiro em assegurar uma assistência livre de danos, seja quando individualmente ou em equipe, devendo avaliar sua competência técnica e legal ao aceitar encargos ${ }^{(12)}$.

O artigo 4 da referida Resolução trata da solicitação de exames de rotina e complementares, a fim de assegurar uma assistência com qualidade. Porém, para compreendermos o respaldo legal do enfermeiro nessas ações, merece destaque o pensamento de França(10) o qual afirma que existe ato médico genérico, lato sensu, compreendido como todo esforço de profissional de saúde não médico para a melhoria da qualidade de vida do ser humano; e, específico ou ato médico propriamente dito, envolvendo a propedêutica e a terapêutica médica, podendo ser desenvolvido inclusive por profissional não-médico, desde que amparado legal e cientificamente, como ocorre com o enfermeiro.

Vários programas de saúde pública e da atenção básica contemplam a possibilidade do enfermeiro em solicitar exames: "Programa DST/AIDS/COAS, Viva Mulher, Assistência Integral e Saúde da Mulher e da Criança, Controle de Doenças Transmissíveis. Além desses, vários Manuais de Normas Técnicas publicadas pelo Ministério da Saúde, também permitem requisições de exames por enfermeiros, como 0 de Capacitação de Enfermeiros em Saúde Pública para o SUS Controle de Doenças Transmissíveis, o Pré-Natal de Baixo Risco, o de Capacitação do Instrutor/Supervisor/Enfermeiro na área de controle da Hanseníase, o de Procedimento para atividade e controle da Tuberculose, 0 de Normas Técnicas e Procedimentos para a utilização dos esquemas de Poliquimioterapia no tratamento da Hanseníase, e o de Normas de atenção à Saúde Integral do Adolescente" ${ }^{\prime(15)}$.

É oportuno destacar que esses programas se encontram, muitos deles, inseridos na proposta para os usuários do PSF, demonstrando, assim, a relevância e confiança que é dada ao profissional enfermeiro nas ações de saúde da atenção básica.
Os artigos 5o e 60 da Resolução em destaque abordam questões referentes respectivamente à consulta de enfermagem com o objetivo de conhecer/intervir sobre os problemas/situações de saúde/doença e diagnosticar e solucionar os problemas de saúde detectados na consulta realizada pelo enfermeiro ${ }^{(12)}$.

Cumpre assinalar que todos os artigos da Resolução 271/2002 estão interligados intrinsecamente e consubstanciados na consulta de enfermagem (Lei 7.498/86, 11,1,i) e na prescrição de medicamentos (Lei 7498/86, $11,1, j)$ legais e tecnicamente preconizados, pois a consulta permeada pelos programas de saúde pública, em especial o PSF, é o cenário onde são levantadas as hipóteses sobre os problemas do paciente, conduzindo o enfermeiro a uma investigação, buscando dados concretos, requerendo exames, alcançando, então, um diagnóstico, que lhe compita uma intervenção legal, culminando com uma eventual prescrição medicamentosa. A ruptura ou impedimento de tais procedimentos, quando necessários, conduz o enfermeiro para um agir omisso, negligente e imprudente que pode colocar em risco a vida do paciente ${ }^{(16)}$.

A própria Portaria do Ministério da Saúde n. 648 do corrente ano, ao abordar as atribuições mínimas e específicas dos membros da equipe de saúde da família, traz as três ações (realizar consulta de enfermagem, solicitar exames e prescrever medicamentos) como atribuições possíveis e legais para o enfermeiro. Ademais, o Conselho Nacional de Educação, através da Resolução 03/2001, reconhecendo a capacidade e competência da formação do profissional enfermeiro, exige que este seja capaz de diagnosticar e solucionar problemas de saúde ${ }^{(15)}$.

Diante destas considerações, podemos perceber a solidez científica, ética e legal das ações do enfermeiro no que tange à prescrição de medicamentos e solicitação de exames, estejam em dispositivos normativos expressos ou facilmente deduzidos, diferentemente dos profissionais médicos que sequer possuem uma Lei que regulamente profissionalmente suas ações. 
Carneiro AD, Morais GSN, Costa SFG, Batista PSS, Costa KC. Prescrição de medicamentos e solicitação de exames por enfermeiros no PSF: aspectos éticos e legais. Rev. Eletr. Enf. [Internet]. 2008; 10(3):756-65. Available from: http://www.fen.ufg. br/revista/v10/n3/v10n3a21.htm

Com isso, o embargo judicial, outorgado pelo TRF-1, constitui em pesar para a enfermagem que vê a decisão como um retrocesso diante dos avanços histórico-legais da profissão, muito embora a decisão esteja em fase recursal e também não afete a permissão oriunda da Lei $7498 / 86^{(11)}$.

Todavia, é fato que estas ações judiciais prejudicam a população, que deixa de receber uma assistência integral e com qualidade nos serviços de saúde da atenção básica, além de desgastarem as relações entre os profissionais enfermeiros e médicos, os quais passam a defender seus interesses classistas, prejudicando o trabalho em equipe, essencial nos programas de saúde pública, como o $\mathrm{PSF}^{(17)}$.

Desta forma, é oportuno destacar uma súmula deste conflito sobre a Resolução 271/2002, à luz da Carta Magna, partindo de estudos de direito constitucional de Miranda(18) e enfatizando alguns argumentos, a fim de propor um caminho para se extinguirem as controvérsias: 1) princípio da liberdade de profissão (art. 5o, XIII, CF) - os médicos defendem seu exercício profissional, embora não possuam ainda Lei que os caracterize, afirmando que os enfermeiros, que se baseiem na referida Resolução para realizarem suas ações, extrapolam os liames da Lei Federal do Exercício Profissional da Enfermagem $n$. $7.498 / 86$; 2) princípio da defesa do direito à saúde (art. 5ㅇ, caput, CF) - um dos argumentos levantados pelo COFEN, dentre vários, num processo judicial ${ }^{(19)}$, era que mais de $80 \%$ dos profissionais da saúde, inseridos em programas de saúde pública eram profissionais de enfermagem, acrescido da escassez de profissionais médicos nos programas que não dariam conta da demanda, considerando assim que a suspensão da Resolução culminaria com um colapso no SUS, ensejando em restrição de direito fundamental ao usuário dos serviços de saúde ${ }^{(17)}$.

Ainda que resgatemos todos os princípios jurídicos sobre o cerne desta questão, jaz à medicina o julgo do princípio da legalidade pelo qual ninguém é obrigado a fazer ou deixar de fazer algo a menos que a lei ordene, uma vez que não há lei do exercício profissional do médico e, por esta razão, os médicos procuram ditar seus parâmetros legais restringindo os dos demais profissionais da saúde.

A atuação do enfermeiro no PSF está amplamente respaldada legalmente, mesmo no que diz respeito à prescrição de medicamentos e solicitação de exames, salientando que ao enfermeiro é dada a oportunidade de "avançar em áreas que vão desde o planejamento e coordenação das ações em saúde até a consulta de enfermagem" ${ }^{\prime 7)}$.

Mediante tais considerações, podemos ressaltar que a prática de enfermagem, no que diz respeito à prescrição de medicamentos, solicitação de exames e consulta de enfermagem, encontra-se disciplinada na lei do exercício profissional 7.498/86.

\section{CONSI DERAÇÕES FI NAIS}

O Programa de Saúde da Família visa, hodiernamente, ser uma estratégia de inclusão social, a partir dos serviços de saúde, numa perspectiva de atenção integral, equânime, humanizada e com qualidade; outrossim, o programa tem tornado mais visível e distinta a profissão do enfermeiro, à proporção em que Ihe são confiados maiores atribuições em conformidade com a Lei Federal 7.498/86 e com o conhecimento técnico-científico conquistados na prática de enfermagem.

Nesse contexto, é que se soerguem as regulamentações legais do Dec. 94.406/87 e a Resolução 271/2002, para possibilitar, na consulta de enfermagem, ao enfermeiro executar com segurança e maestria as ações referentes à prescrição de medicamentos e solicitação de exames. Vale ressaltar que todo o arcabouço das normas de enfermagem enfatiza, para essas ações em especial, o desenvolvimento de um trabalho em equipe, multidisciplinar e com respeito às demais profissões. "O PSF tem por base uma equipe multiprofissional, em que os profissionais passam a ter melhor definição de competências e maior controle de suas atividades, devendo prevalecer o compartilhamento e a confiança mútua em todo o desenvolvimento do processo"(7).

Vale salientar que, diante desse novo horizonte, realçado pelo PSF, reivindica-se do 
Carneiro AD, Morais GSN, Costa SFG, Batista PSS, Costa KC. Prescrição de medicamentos e solicitação de exames por enfermeiros no PSF: aspectos éticos e legais. Rev. Eletr. Enf. [Internet]. 2008; 10(3):756-65. Available from: http://www.fen.ufg.br/revista/v10/n3/v10n3a21.htm

enfermeiro maior domínio sobre as áreas de farmacologia, clínica, fisiologia, entre outras, além de conhecer bem as observâncias éticas e legais que regem sua profissão, a fim de garantir seu espaço e identidade profissional ${ }^{(20)}$.

No que concerne ao exame pormenorizado da Resolução 271/2002, percebemos alguns dos fundamentos que subsidiaram a elaboração desta resolução pelo COFEN, demonstrando que a enfermagem utiliza componentes do método científico para "identificar situações de saúde/doença, prescrever e implementar medidas de enfermagem que contribuam para a comunidade"(16).

Os artigos da resolução delineiam uma única prática de enfermagem, quando em equipe, que é a consulta de enfermagem, podendo, em decorrência dela, a solicitação de exames ou a prescrição de medicamentos em conformidade com os programas de saúde ${ }^{(16)}$.

Considerando a decisão do TRF-1, no processo 2002.00.03.6024-8, em fase recursal, e que comporta reforma por parte dos Tribunais Superiores, acreditamos que tais embates cessarão, confirmando os avanços da ciência de enfermagem e a consolidação da identidade do profissional enfermeiro, reconhecendo mais este espaço como próprio da enfermagem, salvaguardando, assim, os direitos e garantias fundamentais dos usuários dos serviços de saúde da atenção básica(15).

Urge, portanto, que os enfermeiros se dediquem com afinco a sua atividade e se capacitem cada vez mais, não só para uma utilização racional de medicamentos, uma vez que a prescrição medicamentosa não é o aspecto essencial da assistência de enfermagem, mas para manter elevados os ideais de sua profissão, diante de um cotidiano tão desafiador que é o Programa de Saúde da Família.

\section{REFERÊNCI AS}

1. Polignano MV. História das políticas de saúde no Brasil: uma pequena revisão [Internet]. 2006 [cited 2007 jun 30]; Available from: http://www.rnpd.org.br/download/publicacoes/ Saude_no_Brasil.doc.

2. Viana ALD, Poz MRD. A reforma do sistema de saúde no Brasil e o programa de saúde da família. Rev. Saúde Coletiva 2005; 15 Supl:22565.

3. Portal COFEN [Internet]. Rio de janeiro: Conselho Federal de Enfermagem (BR) [update 2007 maio 12, cited 2007 jun 30]. Resolução COFEN 311/2007. Aprova a Reformulação do Código de Ética dos Profissionais de Enfermagem. Available from: http://www. portalcofen.gov.br/2007/materias.a sp?Articlel $D=7221$ \&section $\mathrm{D}=34$.

4. Chiesa AM, Fracolli LA. O trabalho dos agentes comunitários de saúde nas grandes cidades: análise do seu potencial na perspectiva da promoção da saúde. Rev Brasileira Saúde Família. 2004; edição especial(7): 42-9.

5. Costa MBS, Lima CB, Oliveira CP. Atuação do enfermeiro no programa saúde da família (PSF) no Estado da Paraíba. Rev. bras. enferm. 2000; 53(N Esp): 149-52.

6. Sousa MF. A enfermagem reconstruindo sua prática: mais que uma conquista no PSF. Rev. bras. enferm. 2000;53(N Esp): 25-30.

7. Araújo MFS. O enfermeiro no Programa de Saúde da Família: prática profissional e construção de identidade. Rev. Conceitos. 2005; (12): 39-43.

8. Ministério da Saúde. Guia prático do programa saúde da família. Brasília: Ministério da Saúde (BR); 2001.

9. Silva J. Responsabilidade civil do enfermeiro. João Pessoa: Joacir da Silva; 2006.

10. França G. Os limites do ato médico. Medicina Legal [Internet]. 2002 [cited 2006 abr 01]; Available from: http://www. medicinalegal.com. br/a40.htm.

11. Diário da Serra [Internet]. Tangará da Serra: Diário da Serra (MT) [update 2005 maio 11, cited 2007 jul 30]. COREN-MT Comemora o dia internacional da enfermagem. Available from:

http://www. diariodaserra.inf.br/showsaude.asp ?codigo $=87539$

12. Baumann GL. Implicações ético-legais no exercício da enfermagem. 2a edição. Rio de Janeiro: Mondrian; 2004.

13. Portal Médico [Internet]. Brasília: Conselho Federal de Medicina (BR) [cited 2006 out 15]. Prescrição de medicamentos por enfermeiros e outros profissionais não médicos. Available from: 
Carneiro AD, Morais GSN, Costa SFG, Batista PSS, Costa KC. Prescrição de medicamentos e solicitação de exames por enfermeiros no PSF: aspectos éticos e legais. Rev. Eletr. Enf. [Internet]. 2008; 10(3): 756-65. Available from: http://www.fen.ufg. br/revista/v10/n3/v10n3a21.htm

http://www.portalmedico.org. br/atomedico/deci saol.asp.

14. Ferraz F.C. A questão da autonomia e a bioética. Rev Bioética. 2001;9(1):73-82.

15. Piva MG. PARECER ASSJUR/COREN-RS/ 109 -06 [Internet]. 2006 [cited 2006 maio 31].

Available from: http://www.portalcoren-

rs.gov. br/web/resoluca/ResolucaoCOFEN\% 2027 1-2002.pdf.

16. Barbosa JK. Enfermeiros podem prescrever. Rev. COREN-PR [Internet]. 2001 [cited 2006 maio 25];(1). Available from: http://www.corenpr.org.br/revista/1/noticia/17. $\underline{\mathrm{htm}}$

17. Descentralização Online [Internet]. Rio de Janeiro: Ministério da Saúde (BR) [cited 2007 jun 30]. Reuniões da CIT. Reunião da CIT em $30 / 10 / 2002$. Prescrições de medicamentos por enfermeiros. Available from: http://cedoc.ensp. fiocruz.br/descentralizar/deba tes_3. cfm?debate $=58 \& \mathrm{txt}=209$

18. Miranda HS. Curso de direito constitucional. Brasília: Senado Federal; 2006.

19. Tribunal Regional Federal (1aㅡegião). [Internet]. Brasília: Tribunal Regional Federal (BR) [update $2004 \mathrm{fev} \mathrm{15,} \mathrm{cited} 2006 \mathrm{abr}$ 16]. Agravo de Instrumento $\mathrm{n}$. 2004.01 .00 .035700 7/DF. Available from: http://arquivo.trf1.gov. br/AGText/2004/035700 1200401000357007 2.doc.

20. Leal DCMF, Monteiro EM, Barbosa MA. Os horizontes da percepção do enfermeiro do PSF sobre os limites de sua legislação. Revista da UFG [Internet] 2004 [citeded 2006 abr 08];6(N Esp).Available from: http://www.proec.ufg. br/revista_ufg/familia/F horizontes.html

Artigo recebido em 10.07.07

Aprovado para publicação em 30.09.08 